Esta obra está bajo una Licencia Creative Commons Atribución-NoComercial-Compartirlgual 4.0 Internacional

(c) (1) (8) ()

Acerca de la problemática de la reparación de los crímenes de Estado

Ludmila Nair Schneider

DOI: https://doi.org/10.24215/16696581e207

\title{
Acerca de la problemática de la reparación de los crímenes de Estado
}

\section{About the problem of State crimes reparation}

\author{
Ludmila Nair Schneider ludmila.schneider@gmail.com \\ http://orcid.org/0000-0002-3118-6683 \\ Centro de Estudios sobre Genocidio; Universidad Nacional de Tres de Febrero/ Consejo \\ Nacional de Investigaciones Científicas y Técnicas (Argentina)
}

\section{Resumen}

La problemática de la reparación de los actos criminales ejercidos por representantes del Estado contra su propia población ha cobrado un impulso sin precedentes tras la Segunda Guerra Mundial. Desde entonces, programas de diverso alcance han configurado intentos por reparar a las víctimas de graves violaciones a los derechos humanos perpetradas durante 
dictaduras militares o conflictos internos en diversas latitudes. En este paradigma se inscribe esta presentación, cuyo objetivo principal consiste en describir y analizar los lineamientos a partir de los cuales se ha abordado hasta el momento la reparación de los crímenes de Estado. La intención que guía este análisis es identificar sus alcances y limitaciones para construir a partir de una mirada crítica sobre los mismos un marco teórico para la comprensión de la problemática de la reparación.

Para ello, se situará la reparación en el marco de la consolidación de la perspectiva de las víctimas, cuyo punto más álgido de desarrollo lo constituye la concepción de reparación integral. Dado que en ese escenario se sitúa la perspectiva de la justicia transicional, que ha hegemonizado los desarrollos relativos al campo de las reparaciones en las últimas décadas, serán analizados sus postulados principales, profundizando en las múltiples tipologías que se han construido desde la justicia transicional para categorizar las medidas tendientes a la reparación. Para finalizar, se presentarán algunas conclusiones preliminares que deberán ser retomadas en futuros trabajos como puntos de partida para la elaboración de un marco conceptual que permita profundizar la comprensión de la reparación.

Palabras clave: Reparaciones; Justicia transicional; Derechos humanos

\section{Abstract}

The problem of repairing criminal acts pursued by representatives of the State against its own population has gained an unprecedented momentum after the Second World War. Since then, programs of varying scope have configured attempts to repair the victims of serious human rights violations perpetrated during military dictatorships or internal conflicts throughout the world. This presentation is part of this paradigm, whose main objective is to describe and analyze the guidelines from which the reparation of State crimes has been addressed up to now. The intention that guides this analysis is to identify its scope and limitations in order to construct, from a critical view of them, a theoretical framework for the understanding of the problem of reparation.

Reparation will be placed within the framework of the consolidation of the perspective of the victims, whose highest point of development is the concept of integral reparation. Given that the perspective of transitional justice, which has hegemonized the developments related to the field of reparations in the last decades, is situated in this scenario, its main postulates will be analyzed, deepening in the multiple typologies that have been constructed from transitional justice to categorize the measures tending to repair. To conclude, some preliminary conclusions 
will be presented that should be taken up in future work as starting points for the elaboration of a conceptual framework that allows deepening the understanding of reparation

Keywords: Reparations; Transitional Justice; Human rights

\section{Introducción}

La problemática de la reparación de los actos criminales ejercidos por representantes del Estado contra su propia población -entendidos como crímenes de Estado (Chambliss, 1989)ha cobrado un impulso sin precedentes tras la Segunda Guerra Mundial. Frente a la atrocidad del genocidio nazi surge el cuestionamiento filosófico a la posibilidad misma de la reparación, en tanto sus crímenes se presentan como irreparables e imperdonables (Arendt, 1993; Derrida, 2003). Pero a su vez, este acontecimiento sienta las bases para un cambio normativo de carácter internacional que ubica al Estado como responsable de las políticas de reparación a sus ciudadanos.

Desde entonces, programas de diverso alcance han configurado intentos por reparar a las víctimas de graves violaciones a los derechos humanos perpetradas durante dictaduras militares o conflictos internos en Europa Occidental (Pross, 1998), América Latina (de Brito, 2002), Sudáfrica y Europa del Este (Quint, 1997; Pogany, 1997), por mencionar sólo algunos. En este paradigma se inscribe el presente trabajo, cuyo objetivo principal consiste en describir y analizar los lineamientos a partir de los cuales se ha abordado hasta el momento la reparación de los crímenes de Estado. La intención que guía este análisis es identificar sus alcances y limitaciones para construir un marco teórico para la comprensión de la problemática de la reparación, eje central de la investigación doctoral en la que se enmarca el presente trabajo.

Para ello en el próximo apartado se situará la reparación en el marco de la perspectiva de las víctimas, cuyo punto más álgido de desarrollo lo constituye la concepción de reparación integral. Ésta noción será abordada en el apartado tres, junto a las características y tensiones relativas a cada una de las dimensiones involucradas en la misma. Dado que en ese escenario se sitúa la perspectiva de la justicia transicional, el apartado cuatro tendrá por objetivo analizar sus postulados principales. Esta tarea será profundizada en el quinto apartado al presentar las tipologías construidas desde la justicia transicional para examinar las medidas reparatorias. Para finalizar, se presentarán algunas conclusiones que deberán ser retomadas en el futuro como punto de partida para la elaboración de un marco conceptual para la comprensión de la reparación. 
La consolidación de la perspectiva de las víctimas y la reparación como derecho

Previo a la configuración de un régimen de derechos humanos en la sociedad internacional que tuvo lugar como consecuencia de los crímenes cometidos durante la Segunda Guerra Mundial, la normativa relativa a la problemática de la reparación estuvo centrada en las relaciones interestatales. La perspectiva tradicional de la reparación evocaba la responsabilidad de los Estados por los daños producidos injustamente contra otro Estado en el contexto de una guerra, los cuales debían ser reparados una vez finalizado el conflicto. Los protagonistas del proceso de rendición de cuentas eran los perpetradores -agentes del Estado-, y el acento estaba puesto en el castigo a los culpables de los crímenes. Todo agravio que un Estado cometiera al interior de sus fronteras era considerado un asunto de carácter interno, y no existían precedentes históricos ni normas internacionales que incentivaran a los Estados a reparar sus ciudadanos (Wolfe 2003; van Boven 2009).

El acontecimiento histórico que se ubica en la emergencia de la problemática de la reparación de los crímenes de Estado es el genocidio nazi, cuyo horror sistemático impulsó un cambio normativo a nivel mundial a partir del cual el Estado comienza a ser identificado como el responsable de la reparación al interior de sus fronteras. A partir del Acuerdo de Luxemburgo (1952), el reconocimiento progresivo de la situación de las víctimas de los crímenes de Estado ha dado lugar a la consolidación de una perspectiva de las víctimas como eje central para abordar la reparación, de acuerdo a la cual ésta pasa a ser concebida como un derecho de los individuos que han sufrido dichos crímenes en lugar de una prerrogativa interestatal (Gómez Isa, 2007; Van Boven, 2009).

La Declaración Universal de los Derechos Humanos (1948) establecida por Naciones Unidas es un antecedente ineludible en el desarrollo de esta perspectiva, en tanto promovió la noción de dignidad de las víctimas así como su derecho a reclamar reparación ante la justicia. Sin embargo, no fue hasta la adopción de la Declaración sobre los principios fundamentales de justicia para las víctimas de delitos y del abuso de poder (1985) que se configuró el acercamiento global a los derechos de las víctimas (Gómez Isa, 2006). Si bien el castigo a los responsables de los crímenes no se excluye en esta nueva aproximación, el acento está puesto en la situación de la víctima y sus familiares así como en la posibilidad de reparación de los daños sufridos.

Tras la inclusión del derecho de las víctimas a recibir reparación entre las disposiciones del Estatuto de Roma y del mandato para que la Corte Penal Internacional (CPI) establezca principios relacionados con la reparación, la perspectiva de las víctimas cobró relevancia en el ámbito jurídico. Una vasta jurisprudencia de Cortes Internacionales y los estándares de la 
Comisión Interamericana de Derechos Humanos $(\mathrm{CIDH})$ ha contribuido a la interpretación del derecho de las víctimas a obtener reparaciones desde un enfoque integral que trasciende el plano jurídico (Beristain, 2009).

Al no existir tratados internacionales que aborden específicamente el derecho a la reparación, es fundamental la incorporación de instrumentos de derecho internacional de carácter no contractual a la hora de indagar sobre sus alcances. En este sentido, se destacan los Principios y directrices básicos sobre el derecho de las víctimas de violaciones manifiestas de las normas internacionales de derechos humanos y de violaciones graves del derecho internacional humanitario a interponer recursos y obtener reparaciones (2005) -en adelante, Principios (1)-, que si bien no tienen carácter vinculante para los Estados, configuran el instrumento más sistemático para precisar el significado de la reparación.

Vale la pena introducir un aspecto respecto a la normativa que tal como podrá observarse a lo largo de este trabajo, permea todo el desarrollo relativo a la reparación. Frente a la incuestionable importancia de reparar a las víctimas y los enormes esfuerzos en la implementación de medidas a tal fin, la precisión en el diagnóstico acerca de cuál es el daño a reparar no suele colocarse en el centro de estas reflexiones. Esta falencia queda evidenciada en la referencia a las "violaciones manifiestas de las normas internacionales de derechos humanos" o a las "violaciones graves del derecho internacional humanitario" en la jurisprudencia presentada. Se aborda así de manera conjunta la reparación de diversos crímenes, que al menos valdría la pena revisar si ameritan idénticas medidas de reparación o si por el contrario, requieren de abordajes diferenciales. Si bien profundizar en esta indagación excede los límites del presente trabajo, es importante señalar este elemento que alcanza a todos los abordajes de la reparación que serán analizados. Por consiguiente, se hará referencia a las víctimas de graves violaciones a los derechos humanos en la medida en que este es el término propio del campo de las reparaciones pero sin perder de vista la mirada crítica con la que se hace uso del mismo.

Hecho este señalamiento y volviendo a los Principios, su importancia radica no sólo en la cristalización jurídica de la perspectiva de las víctimas, sino en su abordaje desde la perspectiva de la integralidad de la reparación. La misma implica el establecimiento de cinco dimensiones básicas: la restitución, tendiente al restablecimiento de la situación previa de la víctima; la indemnización, referida a la compensación monetaria; la rehabilitación, que comprende medidas tales como la atención médica y psicológica; las medidas de satisfacción, que implica la sanción a los perpetradores y el conocimiento público de la verdad, y la prevención, que pretende brindar garantías de no repetición de las violaciones a los derechos de las víctimas. 
Partiendo de esta concepción, el alcance jurídico de la reparación integral implica la conjunción de diversos aspectos capaces de reparar el daño a las víctimas de violaciones a los derechos humanos. Dada la pluralidad de aspectos contemplados en los Principios, el campo de estudios sobre políticas reparatorias ha abordado cada uno de ellos atendiendo a su singularidad, profundizando en el alcance de las mismas así como dando cuenta de su complejidad. En este marco la propuesta para el próximo apartado es detenerse en cada una de estas dimensiones para explorar sus características y señalar algunas tensiones inherentes a cada una de ellas.

\section{Las dimensiones involucradas en la reparación integral}

En primer lugar, el principio a partir del cual es posible abordar la reparación en términos de restitución establece que todo individuo que haya sido dañado debería ser restituido tan cercanamente como sea posible a la situación anterior a que el daño se produzca (Principios, art. 19). A su vez, la restitución configura la representación simple de la reparación, en tanto el ideal que anima las reparaciones en conjunto es la «plena restitución» (restitutio in integrum), la restauración del statu quo ante (de Greiff, 2006: 415). Dos consideraciones surgen al respecto. La primera es que este principio está orientado hacia el pasado al proponer el regreso a una condición previa a la comisión de los crímenes como objetivo de la reparación. Siguiendo a Wenar (2006), sobre la base de toda teoría de la reparación orientada hacia el pasado existe una noción de restauración moral que indica en sentido metafórico que la tela del orden social ha sido rasgada y debe ser enmendada. Esto resulta particularmente problemático para los casos en los cuales la situación original de las víctimas está caracterizada por vulneraciones de sus derechos humanos. Asimismo, esta perspectiva impide problematizar las condiciones estructurales previas que facilitaron la perpetración de los crímenes de Estado. En este sentido, en sociedades excluyentes y desiguales, cuyas estructuras de exclusión pueden ser consideradas como un factor esencial del conflicto, el propósito de la reparación no puede restringirse a la restitución de la situación en que las víctimas se encontraban previo al régimen en que se cometieron las atrocidades (Uprimmy y Saffón, 2006). Es fundamental considerar por el contrario la dimensión transformadora de la reparación y la orientación de las mismas no sólo hacia el pasado sino principalmente hacia el futuro.

Una segunda consideración está relacionada con la imposibilidad misma de restitución en aquellos casos en que resulta imposible volver lo dañado al estado anterior, como surge claramente en los casos de muerte y desaparición forzada. Si bien se abordará este aspecto en profundidad más adelante, por el momento basta decir que esta limitación puede sortearse asumiendo que incluso cuando los daños son en sí irreparables, es posible avanzar en el 
terreno de la reparación a partir de comprender que toda reparación es simbólica en tanto pretende la restitución no de aquello que se ha perdido, dada su imposibilidad, sino de lo que representa.

Hechas estas consideraciones, debe mencionarse que la dimensión de la restitución incluye no sólo el restablecimiento de derechos vulnerados sino también aspectos materiales concretos como ser el retorno al lugar de residencia, la devolución de bienes y el empleo. En cuanto a la problemática relativa a la restitución de la tierra, debe destacarse que los desplazamientos masivos, el abandono de hogares y territorios por parte de la población se encuentran entre las consecuencias de las violaciones a los derechos humanos, que en ocasiones se insertan en una larga lucha por el derecho a la propiedad de la tierra por parte de comunidades despojadas de sus territorios ancestrales (Beristain, 2009; Leckie, 2005).

En segundo lugar, en cuanto a la dimensión relativa a la indemnización, ésta

Ha de concederse, de forma apropiada y proporcional a la gravedad de la violación y a las circunstancias de cada caso, por todos los perjuicios económicamente evaluables que sean consecuencia de violaciones manifiestas de las normas internacionales de derechos humanos o de violaciones graves del derecho internacional humanitario (Principios, art. 20)

Así entendida, la reparación compensatoria se reduce a términos financieros y se instrumenta mediante el otorgamiento de indemnizaciones económicas (Valls, 2003), constituyendo uno de los elementos más recurrentes en el diseño de medidas reparatorias, cuyo aspecto más controversial reside en la valuación económica de los daños producidos por las violaciones de los derechos humanos.

En cuanto a los daños que pueden dar lugar a la indemnización cuentan primeramente los daños materiales, que abarcan tanto el daño emergente como el lucro cesante. Mientras que el primero refiere a los daños patrimoniales producidos directamente por los crímenes perpetrados, el segundo se relaciona con aquello que la víctima dejó de percibir como consecuencia de dichos crímenes, en tanto pérdida de ingresos económicos futuros que hubieran ingresado a su patrimonio si las violaciones no hubieran ocurrido. Pero además, la dimensión indemnizatoria de la reparación propone la cuantificación -el establecimiento en términos contables- de daños morales, físicos y psicológicos que la víctima ha sufrido como consecuencia de la violación de sus derechos.

En otras palabras, la indemnización entendida como compensación se refiere a las medidas que buscan compensar los daños sufridos a través de la cuantificación de dichos daños, desde 
una perspectiva que comprende el daño como algo que trasciende la esfera económica e incluye lesiones físicas, psicológicas y morales, la pérdida de oportunidades de empleo, educación y prestaciones sociales (De Greiff, 2008: 409) o incluso conceptos menos precisos como el «daño al proyecto de vida» (Siri, 2011) (2).

No sólo hay circunstancias en las cuales el ideal de compensación no es realizable sino que además en este caso, este aspecto está relacionado con la dificultad que supone asignar valores a los distintos tipos de daños de manera efectiva y confiable. En este sentido, la cuantificación del daño ocasionado a las víctimas sobre el principio de las "compensaciones efectivas" o "compensación en proporción al daño" aparece como problemática: ¿Cuánto vale la pérdida de un ser querido, el sufrimiento ocasionado por la tortura o el trauma psicológico? Incluso suponiendo que el valor del daño puede ser establecido ¿permanece invariable para todas las personas afectadas?

De esto se desprende que la determinación de los montos a otorgar en materia de indemnización, así como las modalidades en que se implementan los pagos tienen siempre un cierto grado de arbitrariedad y dependen de generalizaciones y presupuestos establecidos procedimentalmente tanto por las cortes internacionales como por los programas masivos de reparación, muchas veces de acuerdo a criterios dispares.

Por último, la reparación económica genera dilemas éticos por parte de las víctimas sobre «su significado, el sentido de la aceptación, la relación con la pérdida y el contexto o la manera en que se produce» (Beristain, 2009:251). Esta experiencia puede ser conceptualizada como el choque de dos universos de sentidos diametralmente opuestos: por un lado, la trama de significación inscripta en la condición de víctimas de graves violaciones a los derechos humanos, por el otro, el universo del dinero, en tanto equivalente general de las mercancías (Surraco, 2013).

Una tercera dimensión comprendida en la reparación integral es la rehabilitación, que contempla la atención médica y psicológica, así como la provisión de servicios jurídicos y sociales a las víctimas (Principios, art. 21). Estas medidas tienen por objetivo contrarrestar los efectos negativos para la salud en términos de enfermedades y deterioro de las condiciones de vida, así como de las situaciones traumáticas que han atravesado las víctimas como consecuencia de las violaciones sufridas. En cuanto a las medidas en salud, éstas pueden implementarse siguiendo diversos modelos como el reembolso de los gastos médicos solventados por las víctimas o la atención a través de los servicios públicos (Beristain, 2009). Por otra parte, se ha destacado la importancia de asumir una perspectiva psicosocial en la implementación de medidas de rehabilitación, en tanto aspecto fundamental para la articulación del proceso de implementación de la reparación con los procesos individuales y familiares de 
las víctimas, que muchas veces se encuentran regidos por tiempos, lógicas y necesidades diferentes. El acompañamiento a las víctimas -que refiere al trabajo con las víctimas teniendo en cuenta sus propias necesidades- resulta un aspecto clave para impedir su revictimización y supone la actuación de profesionales de la salud mental (Beristain, 2009, 44-61).

En la misma línea, la rehabilitación se ha abordado como un componente esencial del proceso ligado a la recuperación de las víctimas en tanto superación de las secuelas del «trauma masivo» (Danieli, 2009). A tal fin, la rehabilitación comprende intervenciones psicosociales y acompañamiento de salud mental a víctimas y sobrevivientes desde un abordaje que se propone trascender el paradigma dominante de la psicología clásica basada en la medicalización para la curación de trastornos post traumáticos (Lykes \& Mersky, 2006). Por el contrario, los abordajes psicosociales consideran a los individuos, familias y comunidades insertos en los contextos históricos y socioculturales en los cuales las violaciones han ocurrido, con la intención de promover la reconstrucción de los lazos sociales vulnerados (Lykes \& Mersky, 2006, 2006; Villa, 2012).

Por último, tanto la dimensión relativa a la satisfacción como la asociada a las garantías de no repetición configuran dos categorías especialmente amplias entre las que cuentan una multiplicidad de medidas muy diversas y que ha dado lugar a su conceptualización en tanto medidas de reparación simbólica (Gómez Isa, 2006; de Greiff, 2008), categoría que será problematizada en el próximo apartado.

Interesa señalar que las medidas de satisfacción están orientadas al conocimiento público de la verdad de lo sucedido con el objetivo de dignificar a las víctimas, y entre las mismas cuentan la investigación y difusión de la verdad, la búsqueda de las personas desaparecidas, los actos oficiales de disculpas públicas, la sanción a los responsables de los crímenes y las conmemoraciones y homenajes a las víctimas (Principios, art. 22). Estas medidas permiten aprehender la vinculación que existe entre la justicia, la verdad y la reparación, dimensiones profundamente imbricadas que difícilmente puedan ser pensadas escindidas entre sí.

Un aspecto relevante entre las medidas de satisfacción a considerar es el proceso de juzgamiento a los responsables de los crímenes de Estado como un elemento fundamental de la reparación. En términos históricos, los Juicios de Nuremberg son un antecedente ineludible en cuanto al desarrollo de jurisprudencia internacional que posibilitó la realización de juicios por violaciones masivas a los derechos humanos, ya sea por tribunales internacionales como por tribunales de justicia local durante todo el Siglo XX y lo que va del Siglo XXI. En lo que hace a los procesos de juzgamiento, así como se ha puntualizado en la potencialidad reparatoria de los juicios (Douglas, 2005; Sikkink, 2011), es necesario señalar que la misma depende en gran medida de las características que estos asumen en cada caso, atendiendo al cómo se 
desarrollan los mismos, en tanto determinadas circunstancias pueden provocar la revictimización de las víctimas durante el proceso de juzgamiento, especialmente a la hora de brindar testimonio (Dembour \& Haslam, 2004; Beristain, 2009).

A su vez, otra de las medidas de satisfacción a destacar es el desarrollo de comisiones de la verdad. Su implementación suele tener lugar en el marco de las transiciones hacia gobiernos democráticos y persigue el objetivo de llevar adelante una investigación oficial respecto de las violaciones de derechos humanos perpetradas durante el régimen saliente. Frente a las limitaciones que presentan los contextos transicionales para el juzgamiento de los criminales, la constitución de comisiones de la verdad configuran un modo de respuesta por parte del Estado a los abusos del pasado reciente (Hayner, 2008). Considerando que las mismas no poseen potestades judiciales, su contribución principal se vincula con su capacidad para realizar una interpretación de los hechos investigados con enorme incidencia en la construcción de la memoria colectiva de las sociedades posconflicto, debido a su habilidad para construir narrativamente un puente histórico entre un pasado caracterizado por el terror y un futuro en el que prime el reconocimiento por los derechos humanos (Grandin, 2007). Dado que son impulsadas por el Estado, estas investigaciones configuran una memoria oficial sobre lo sucedido que forma parte de la lucha entablada en el plano simbólico por la construcción de sentidos sobre la experiencia atravesada.

Profundizando en este aspecto, son múltiples los actos de memoria que participan de esta lucha simbólica y que se encuentran comprendidos dentro de las medidas de satisfacción. Entre ellos se destaca la marcación de territorios y lugares identificados como espacios en los cuales ocurrieron las violaciones a los derechos humanos, así como la construcción de memoriales y monumentos en recuerdo de las víctimas (Nora, 2008; Jelin y Langland, 2003). Estas prácticas se inscriben en un proceso de memorialización, entendido como la cristalización de los modos en que la sociedad recuerda y elabora el pasado, el cual combina la necesidad individual de recordar a las víctimas con la aspiración colectiva de narrar la historia y plasmarla en el espacio público (Schindel, 2009).

Las medidas de satisfacción están permeadas también por la cuestión del reconocimiento. La reparación como reconocimiento articula la violación de los derechos fundamentales del individuo con la vulneración de la ciudadanía. Partiendo de allí, toda medida tendiente a institucionalizar el reconocimiento del individuo como ciudadano puede ser interpretada como un acto de reconocimiento, que implicaría devolver -o si fuera necesario, establecer por primera vez- a los individuos su estatus de ciudadanos. El reconocimiento implica reconocer al sujeto a la vez como individuo, como ciudadano y como víctima (De Greiff, 2006; Beristain, 2009). 
Finalmente, la asunción de responsabilidad por parte del Estado expresada en el reconocimiento de lo ocurrido reviste una importancia central a partir de la cual propiciar un cambio en la relación entre el Estado y las víctimas sobre la base de la confianza cívica, entendida como la capacidad del Estado de generar una confianza social que permita a los ciudadanos desarrollar un sentido mutuo de compromiso con las normas y valores compartidos (De Greiff, 2006).

De lo anterior se desprende que los actos de reconocimiento están fuertemente vinculados a las garantías de no repetición. Con el objetivo explícito de contribuir a la prevención de futuras violaciones, éstas consisten en reformas institucionales que van desde el control afectivo de las fuerzas armadas por parte de las autoridades civiles hasta el fortalecimiento de la independencia judicial, y otras medidas tendientes a la consolidación de la democracia y la promoción de los derechos humanos (Principios, art. 23).

El reconocimiento puede ser concebido como un modo de prevención en la medida en que los actos de reconocimiento pueden tener un valor educativo para el conjunto de la sociedad así como para las fuerzas de seguridad en particular, y a su vez, pueden convertirse en la expresión de un compromiso de ruptura con la práctica de las violaciones (Beristain, 2009). Las garantías de no repetición plantean a su vez la necesidad de llevar adelante reformas estructurales en el funcionamiento del Estado que incluyen cambios en los procedimientos administrativos, puesta en marcha de mecanismos de control y la formación de funcionarios en el campo de los derechos humanos, entre otras. En definitiva, el postulado fundamental que atraviesa la concepción de las garantías de no repetición indica que la implementación de cambios institucionales podrá evitar la comisión de graves violaciones a los derechos humanos en el futuro.

Habiendo presentado las dimensiones asociadas a la reparación integral y las principales tensiones que las atraviesan, debe señalarse que las mismas han sido recuperadas por el campo de estudios de la justicia transicional. Esta perspectiva teórico política ha hegemonizado los debates en torno a la reparación a partir de su surgimiento y consolidación a mediados de la década del 80 . El próximo apartado estará dedicado a desarrollar sus principales características y señalar las limitaciones que presenta para la comprensión de la problemática de la reparación.

\section{La reparación desde la perspectiva de la justicia transicional}

De acuerdo al campo de estudios de la justicia transicional, las medidas de reparación se inscriben en los procesos de transición de un régimen político a otro, durante el cual los 
gobiernos democráticos asumen la responsabilidad de la rendición de cuentas por los crímenes cometidos por regímenes políticos antecedentes (Kritz, 1995; Elster, 2006; de Greiff, 2008). En una primera aproximación, la justicia transicional puede ser definida como un proceso de justicia que involucra una diversidad de aspectos complejos de distinta duración en el tiempo y que en cada sociedad concreta puede tomar formas específicas muy diferentes entre sí. En tanto proceso de justicia, esta perspectiva le otorga un papel constitutivo al cambio normativo fundamentado en las respuestas legales que se implementan en los períodos de transición para lidiar con el pasado represivo.

Elster define la justicia transicional como aquella que «se compone de los procesos de juicios, purgas y reparaciones que tienen lugar luego de la transición de un régimen político a otro» (2006:15). Por su parte, la definición del International Center of Transitional Justice (ICTJ) especifica que

La justicia transicional es el conjunto de medidas judiciales y políticas que diversos países han utilizado como reparación por las violaciones masivas de derechos humanos. Entre ellas figuran las acciones penales, las comisiones de la verdad, los programas de reparación y diversas reformas institucionales.

En un trabajo anterior se han analizado en detalle los principales postulados de la justicia transicional, considerando el modo en que desde esta perspectiva se concibe la justicia, la transición y la democracia. Allí se ha señalado que sus diversas acepciones enfatizan su naturaleza transitoria sin definir exactamente en qué consiste el estado postransicional que se encuentra en el horizonte de estas medidas. De este modo, el horizonte liberalizador que subyace a la justicia transicional se fundamenta en las concepciones morales y políticas ideales del estado de derecho adaptadas a contextos de profundas transformaciones sociales. La jurisprudencia de transición plasma dichas concepciones ideales en programas de reparaciones concretos de cobertura masiva entendidos como «conjuntos más o menos coordinados de medidas de reparación», mediante los cuales se «ofrecen beneficios directamente a las víctimas de ciertos tipos de crímenes» (De greiff, 2006: 410).

La definición de la justicia transicional no configura una concepción acaba sino que hace referencia a una noción de justicia que sólo es esbozada con contornos imprecisos. Lejos de constituir un tipo particular de justicia en términos filosóficos, parece referir a determinadas circunstancias en las cuales puede tener lugar -o no, dependiendo de cada caso- la justicia en términos concretos. 
A la luz de estas consideraciones, algunos autores sostienen que los procesos referidos como transiciones hacia la democracia desde el campo de la justicia transicional podrían definirse más específicamente como una conversión a una definición particular de democracia, centrada en los derechos políticos y legales en detrimento de los derechos sociales (Grandin, 2007; Castillejo Cuellar, 2017). En oposición al abordaje de la justicia transicional que construye narrativamente una fractura radical entre el pasado y el futuro mediante la promesa de construcción de una nueva sociedad, esta perspectiva -que aquí será referida como crítica al paradigma transicional- pone de relieve la importancia de hacer visible la dialéctica entre las fracturas y las continuidades que caracterizan el proceso de la transición. Este abordaje plantea que la justicia transicional invisibiliza la continuidad de las diversas formas de violencia intrínsecas al capitalismo mediante la presentación del escenario transicional como un momento en el cual se presenta la ilusión de la emergencia de nuevas configuraciones sociales, sobre el establecimiento de una línea imaginaria entre un "pasado violento" y un "futuro porvenir".

Se ha dicho que uno de los problemas que atañe a los desarrollos relativos a la reparación es que los mismos no parten de un diagnóstico preciso acerca de los daños a reparar, refiriendo indistintamente a la reparación de graves violaciones a los derechos humanos y crímenes internacionales entre los que se incluye los crímenes de guerra, el genocidio y los crímenes de lesa humanidad. Al profundizar en las concepciones que subyacen a la justicia transicional, se evidencia que tampoco es posible discernir claramente cuál es el horizonte de la reparación, más allá de vislumbrarse una orientación hacia un paradigma ideal asociado a la reconstrucción de un estado de derecho. La explicitación de este horizonte no sólo otorga sentido a las medidas reparatorias, sino que también resulta una guía fundamental para el proceso de construcción, implementación y evaluación de las mismas, por lo cual deberá ser especialmente considerado si se quiere construir un abordaje que permita comprender la problemática de la reparación en toda su complejidad.

Ahora bien, incluso teniendo en cuenta las limitaciones de esta perspectiva, uno de sus principales aportes a los estudios sobre la reparación reside en las múltiples tipologías construidas para analizar las medidas reparatorias. El universo de medidas reparatorias es categorizado considerando diversas variables como las más relevantes para la comprensión de los procesos tendientes a la reparación. Estas categorizaciones constituyen el eje del análisis del próximo apartado. 
Las tipologías construidas para analizar las medidas reparatorias

A continuación se presenta una propuesta de sistematización de las tipologías a partir de las cuales la justicia transicional ha analizado las medidas reparatorias. La misma no persigue fines exclusivamente descriptivos sino que está construida con el fin de problematizar algunas categorías ampliamente utilizadas en diversos programas de reparaciones implementados en los últimos años, así como recuperadas por numerosos autores dedicados al estudio de la reparación.

En este marco, uno de los desarrollos más extendidos es el que puntualiza en la forma de justicia involucrada en las medidas reparatorias. Es importante señalar que éstas no aluden a la justicia en términos filosóficos sino que refieren al tipo de respuestas legales involucradas en las medidas reparatorias, entendidas como el objetivo que persigue la justicia en términos institucionales en períodos de transición. En este sentido, es pionera la publicación de Kritz (1995) que distingue entre la justicia penal y la justicia no penal. Si bien la justicia transicional no puede ser discutida sin considerar su aspecto punitivo dada la importancia que reviste la cuestión de la responsabilidad así como la impunidad (Schabas, 2011), esta distinción deja ver la necesidad de pensar la justicia más allá del castigo a los responsables de los crímenes.

Teitel (2000) complejiza esta distinción y propone que así como la justicia transicional está compuesta por la justicia penal, también deben considerarse la justicia histórica -referida a las leyes que impulsan la investigación de lo sucedido-, la justicia administrativa -que redefine los parámetros de conformación de la comunidad política vulnerados durante el régimen antecedente mediante el derecho público-, la justicia constitucional-expresada en las reformas constitucionales que dan origen al nuevo orden político- y la justicia reparatoria. Esta última se compone por las iniciativas centradas en la reivindicación de los derechos de las víctimas, independientemente de las medidas concretas que sean promovidas a tal fin y la esfera del derecho en el que las mismas se inserten, involucrando así un amplio conjunto de medidas. La elección del término justicia reparatoria en tanto acepción restringida de la reparación puede dar lugar a cierta confusión, ya que las medidas asociadas a los demás tipos de justicia también comparten la intención de reparar a las víctimas, diluyendo así su especificidad.

Enfatizando en la importancia de que estos tipos de justicia sean llevados a cabo por el Estado que ha cometido las atrocidades a reparar, Wolfe (2011) retoma la tipología de Teitel e introduce dos modificaciones. En primer lugar, propone que la justicia administrativa así como la justicia constitucional sean ambas consideradas como justicia legislativa, en tanto se fundamentan en la instauración de medidas legislativas; y en segundo lugar, la verdadera novedad está en la incorporación de la categoría de justicia simbólica para abarcar aquellas 
acciones realizadas por el estado que tienen significado simbólico, tales como la emisión de disculpas públicas y la creación de monumentos conmemorativos.

Por último, Elster (2006) realiza un aporte interesante al agregar entre las formas institucionales la justicia política, referida a la parcialidad en la administración de las demás formas de justicia por parte de los nuevos gobiernos, cuando de manera unilateral y sin posibilidad de apelación señalan a los criminales y deciden qué hacer con ellos.

Volviendo a la dimensión simbólica de las reparaciones a la que hacía referencia la justicia simbólica, ésta ha sido señalada en un segundo grupo de tipologías que apuntan a caracterizar las formas que asume la reparación, intentando trascender su perspectiva jurídica para analizar las medidas contenidas en los programas de reparaciones de cobertura masiva para las víctimas de determinados crímenes.

En primer lugar, al interior del universo de medidas contenidas en dichos programas se distingue entre las reparaciones materiales, que incluyen compensaciones económicas así como paquetes de servicios como ser la provisión de educación, salud y vivienda; y las reparaciones simbólicas, comprendidas por ejemplo por disculpas oficiales, medidas de rehabilitación y la creación de días de conmemoración. Mientras que algunos autores presentan ambas categorías como excluyentes (De Greiff, 2008, Gómez Isa, 2006), otros señalan que toda reparación tiene un componente simbólico, especialmente desde la perspectiva de las víctimas, para quienes el significado de toda medida tendiente a reparar los daños implica un reconocimiento orientado a restablecer su dignidad (Beristain, 2009; Hamber, 2006). En este caso, se postula que la particularidad de las medidas de reparación simbólica se sitúa en el terreno de la construcción de sentido sobre los hechos ocurridos -aspecto que bien puede decirse corresponde a toda medida reparatoria-, ampliando incluso los límites de esta categoría para incluir medidas materiales como la construcción de un memorial o el cambio de nombre de una calle en rememoración de las víctimas. En este punto, la distinción entre reparación materiales y simbólicas se vuelve difusa.

En aras de clarificar esta confusión, se postulará en primer lugar que la reparación siempre es simbólica. Si los daños que producen los crímenes de Estado son en sí irreparables en tanto no es posible volver lo que se ha lesionado al estado anterior a producido el daño, la reparación no pretende la restitución de aquello que se ha perdido, dada su imposibilidad, sino de lo que representa. Introduciendo una reflexión desde la perspectiva psicoanalítica,

La reparación es simbólica porque pretende una compensación que siempre es un desplazamiento desde el daño real hacia un acto de justicia, pretende 
representarlo en magnitud cualitativa o cuantitativamente, pero nunca repara el daño real producido sobre la víctima (Guilis, 2004).

A partir de considerar toda medida reparatoria como simbólica, una distinción que vale proponer y que se considera que contribuye a una comprensión más adecuada acerca de la reparación, sería aquella que partiendo de considerar que todas las medidas comparten la dimensión simbólica, permita diferenciar entre medidas de reparación materiales e inmateriales, incluyendo así en estas últimas aquellas categorizadas como medidas simbólicas de reparación.

En segundo lugar, para analizar las formas que asume la reparación se distingue entre las reparaciones individuales y las reparaciones colectivas para hacer referencia a la distribución de cualquiera de las formas de reparación mencionadas. Esta categorización está vinculada al carácter de la víctima, y apunta a diferenciar entre los daños individuales que han afectado a las personas y los daños colectivos sufridos por los grupos victimizados (De Greiff, 2008; Beristain, 2009; Van Bowen, 2003).

Una primera indicación al respecto es que no basta con que las medidas reparatorias estén dirigidas a un alto número de víctimas para ser consideradas colectivas, por lo tanto deben diferenciarse entre las reparaciones colectivas y las reparaciones masivas o procesos de reclamos masivos. Hablar de lo colectivo aquí no significa una suma de personas. Más precisamente, la reparación colectiva evoca las medidas tendientes a reconstruir las comunidades afectadas a través de medidas de impacto colectivo situadas en el contexto de una comunidad (Beristain, 2009). $\mathrm{Y}$ en este sentido, una dificultad que presenta esta categorización es la naturaleza individualizada de muchos de los procedimientos mediante los cuales se implementan las reparaciones, incluso en los casos de víctimas de daños colectivos (Oette, 2009).

Ahora bien, toda vez que los daños individuales y colectivos se encuentran estrechamente relacionados, las reparaciones individuales y colectivas pueden ser pensadas no como dos formas excluyentes que puede asumir la reparación sino como dos dimensiones a considerar en toda medida reparatoria. Resulta sugerente la propuesta de Hamber (2006) para quien toda medida involucra una dimensión micro -centrada en las víctimas individuales- y una dimensión macro. Esta última no sólo es colectiva porque está dirigida a reparar los daños sufridos por las colectividades o grupos afectados, sino que pretende tomar en consideración los efectos de las medidas reparatorias en el mundo de lo social y lo político en el cual se inscriben los programas de reparaciones. 
Habiendo revisado la multiplicidad de tipologías propuestas para categorizar las medidas implementadas en los procesos de justicia de transición, se evidencia la fuerte vinculación existente entre este campo de estudios y la problemática de las reparaciones. Ya sea por concebir la reparación en sentido amplio como el objetivo al que tienden las medidas transicionales como una totalidad; ya sea por señalar la importancia de las medidas reparatorias como un elemento que forma parte de un conjunto más amplio de medidas, la dimensión reparatoria se encuentra siempre presente en los esfuerzos por conceptualizar la justicia transicional.

Sin embargo, la justicia transicional no aporta precisiones respecto de cuál es el horizonte de la transición ni tampoco parte de un diagnóstico acerca de qué es lo que las múltiples medidas analizadas deberían reparar. Los autores reseñados abordan la problemática de la reparación de los crímenes de guerra, los crímenes de lesa humanidad, el crimen de genocidio y las violaciones a los derechos humanos de manera indistinta, avanzando en postular la importancia que reviste la reparación de estos crímenes para construir una sociedad sin violencia en el futuro pero sin precisar los alcances, las características ni las implicancias diferenciales de los mismos en profundidad. Es por ello que si bien las tipologías presentadas permiten describir exhaustivamente las medidas tendientes a la reparación, la fecundidad de esta perspectiva a la hora de comprender más profundamente la problemática de la reparación parece presentar algunas limitaciones.

\section{A modo de conclusión}

En este trabajo se ha reflexionado acerca de la producción existente en el campo de las reparaciones con el objetivo de identificar los límites y potencialidades que presentan para la comprensión y el estudio de esta problemática. Para ello, se comenzó situando históricamente la emergencia de este campo de estudios así como el desarrollo normativo y jurisprudencial que acompañó este proceso hasta su cristalización en los Principios de la ONU relativos a la reparación integral, cuyas dimensiones fueron analizadas detalladamente. Este análisis permitió dar cuenta de las tensiones inherentes a cada una de estas dimensiones, las cuales en muchas ocasiones se solapan unas con otras dando lugar incluso a ciertas confusiones conceptuales.

A su vez, la relevancia que adquirió la perspectiva de la justicia transicional en las últimas décadas hizo necesario analizar esta perspectiva así como las tipologías que desde la misma se construyeron para categorizar las medidas tendientes a la reparación. De este análisis se desprendió que muchas de las categorías construidas presentan ciertas imprecisiones, y que 
es necesario reformularlas para contribuir a una comprensión más acabada de la problemática bajo estudio. Más allá de estas particularidades, interesa poner de relieve dos cuestiones centrales que atraviesan el abordaje de la reparación de manera general y que resulta imperativo repensar para avanzar hacia conceptualizaciones superadoras. La primera de ellas se relaciona con la falta de un diagnóstico explícito acerca de los daños que la reparación tiene por objetivo; la segunda, con la imprecisión del horizonte de la reparación hacia el futuro.

Todas las caracterizaciones analizadas parten del supuesto de la necesidad de reparar crímenes atroces e imperdonables: violaciones graves de los derechos humanos, crímenes de lesa humanidad, crímenes de guerra y genocidio, entre otros. La reparación de una multiplicidad de crímenes que requieren abordajes diferenciales se presenta de manera indistinta, invisibilizando la especificidad propia de cada uno de ellos. Un diagnóstico preciso acerca de los daños que fundamentan la reparación aparece como un elemento central a considerar para construir un marco conceptual para el estudio de la misma.

Por otra parte, otro aspecto que aparece como un obstáculo a sortear se relaciona con la necesidad de definir la orientación de la reparación, es decir, con el horizonte que persigue la implementación de medidas reparatorias. Esto se ha visto muy especialmente en el caso de la justicia transicional, que postula la necesidad de construir una sociedad democrática basada en el estado de derecho, pero a la vez esconde que las transiciones implican continuidades con formas de violencia que se encuentran en la base de los conflictos que se quiere reparar. Hacia dónde debe construirse la transición, es la pregunta a la que la justicia transicional no parece dar respuesta y que en definitiva contiene en su seno el sentido último de la reparación.

En síntesis, será necesario tomar nota de las consideraciones aquí vertidas como punto de partida para la construcción de un marco conceptual mediante el cual sea posible abordar la compleja problemática de la reparación situando la misma en el entramado de relaciones sociales en las cuales ésta tiene lugar. Para ello, será fundamental considerar no sólo cuáles son los daños que es necesario reparar, sino también cuál es la sociedad que la reparación contribuye a construir de cara al futuro.

Notas

(1) Aprobados por la Asamblea General de las Naciones Unidas mediante resolución A/RES/60/147 del 24 de octubre de 2005. Recuperado de http://www.ohchr.org/SP/Professionallnterest/Pages/RemedyAndReparation.aspx [Consultado el 03/01/2019] 
(2) El daño al proyecto de vida surge de las sentencias dictadas por la CIDH y atiende a "la realización integral de la persona afectada, considerando su vocación, aptitudes, circunstancias, potencialidades y aspiraciones, que le permiten fijarse razonablemente determinadas expectativas y acceder a ellas" (Corte IDH. Caso Loayza Tamayo Vs. Perú. 27/11/1998. Serie C 42 párr. 147)

\section{Bibliografía}

Arendt, H. (1993). La condición humana, Paidós, Barcelona.

Beristain, C. M. (2009). Diálogos sobre la reparación: qué reparar en los casos de violaciones de derechos humanos. Ministerio de Justicia y Derechos Humanos.

de Brito, A. B. (2002). Verdad, justicia, memoria y democratización en el Cono Sur. En Las políticas hacia el pasado: Juicios, depuraciones, perdón y olvido en las nuevas democracias, Ediciones Istmo.

Castillejo Cuéllar, A. (2017). La ilusión de la justicia transicional Perspectivas críticas desde el Sur global. Ediciones Uniandes, Bogotá.

Chambliss, W. (1989). "State organised crime", en Criminology, número 27, pp 183-208

Colonomos, A.; Armstrong, A. (2006). German Reparations to the Jews after World War Two: A Turning Point in the History of Reparations, en, In Pablo De Greiff, The Handbook of Reparations. Oxford, New York, USA: Oxford University Press. Pp. 390-419.

Danieli, Y. (2009). Massive Trauma and the Healing Role of Reparative Justice. In Ferstman, C., Goetz, M., \& Stephens, A. (Eds.): Reparations for victims of genocide, war crimes and crimes against humanity: systems in place and systems in the making, Brill.

De Greiff (2005). "Los esfuerzos de reparación en una perspectiva internacional: el aporte de la compensación al logro de la justicia imperfecta". Revista Estudios Socio-Jurídicos, Vol 7, pp 153-199, Bogotá, Colombia.

De Greiff, P. (Ed.). (2006). The handbook of reparations. Oxford University Press.

De Greiff, P. (2008). "Justicia y Reparaciones". En Reparaciones a las víctimas de la violencia política: estudios de caso y análisis comparado, Catalina Diaz (org.), ICTJ, Bogotá.

Dembour, M. B., \& Haslam, E. (2004). Silencing hearings? Victim-witnesses at war crimes trials. European Journal of International Law, 15(1), 151-177.

Derrida, J. (2003). El siglo y el perdón (entrevista con Michel Wieviorka), Ediciones de la Flor.

Douglas, L. (2005). The memory of judgment: Making law and history in the trials of the Holocaust. Yale University Press. 
Elster, J.: (2006). Rendición de cuentas. Katz Editores, Buenos Aires.

Fraser, N., \& Honneth, A. (2003). ¿Redistribución o reconocimiento? Un debate político filosófico, Ediciones Morata. Capítulo 1: "La justicia social en la era de la política de identidad: redistribución, reconocimiento y participación" (Fraser, 2003: 17-88)

Gómez Isa, F (2007). "El derecho de las víctimas a la reparación por violaciones graves y sistemáticas de los derechos humanos". El Otro Derecho no. 37. Bogotá : ILSA y

Grandin, G. (2007). Las instrucciones de las grandes catástrofes: comisiones por la verdad, historia nacional y formación del Estado en Argentina, Chile y Guatemala. En Revista Sociohistórica, 21/22, FaHCE/UNLP, La Plata.

Guilis, Graciela y Equipo de Salud mental del CELS (2004). "El concepto de reparación simbólica". Disponible en: www.cels.org.ar [consultado el 05/01/2016]

Hamber, B. (2006). Narrowing the Micro and macro: A Psychological Perspective on reparations in Societies in Transition. En Pablo De Grieff (Ed.) The Handbook of Reparations.Oxford University Press.

Hayner, P. (2008). Verdades innombrables. El reto de las comisiones de la verdad, Fondo de Cultura Económica.

Jelin, E., \& Langland, V. (2003). Monumentos, memoriales y marcas territoriales (Vol. 5). Siglo XXI de España Editores.

Kritz, N. J. (Ed.). (1995). Transitional justice: how emerging democracies reckon with former regimes (Vol. 1). US Institute of Peace Press.

Lykes, M. B., \& Mersky, M. (2006). Reparations and mental health: Psychosocial interventions towards healing, human agency, and rethreading social realities, in De Greiff (2006).

Leckie, S (2005). Housing, Land and Property Rights in Post-Conflict Societies: Proposals for a New United Nations Institutional and Policy Framework (UNHCR, Geneva).

Nora, P. (2008). Pierre Nora en Les lieux de mémoire. Ediciones Trilce.

Oette, L. (2009). Bringing justice to victims? Responses of regional and international human rights courts and treaty bodies to mass violations, in Reparations for Victims of Genocide, War Crimes and Crimes against Humanity (pp. 215-242). Brill.

Pogany, I. S. (1997). Righting Wrongs in Eastern Europe. Manchester University Press.

Pross, C. (1998). Paying for the past: The struggle over reparations for surviving victims of the Nazi terror, JHU Press.

Quint, P. (1997). The imperfect union: constitutional structures of German unification. Princeton University Press.

Schindel (2009). Inscribir el pasado en el presente: memoria y espacio urbano. En Política y cultura, (31), 65-87.

Question, Vol. 1, N. ${ }^{\circ}$ 64, octubre-diciembre 2019. ISSN 1669-6581

Instituto de Investigaciones en Comunicación | Facultad de Periodismo y Comunicación Social | Universidad Nacional de La Plata La Plata | Buenos Aires | Argentina

Página 20 de 21 
Sikkink, K. (2011). The Justice Cascade: How Human Rights Prosecutions Are Changing World Politics (The Norton Series in World Politics).

Siri, A. J. R. (2011):.El concepto de reparación integral en la jurisprudencia de la Corte Interamericana de Derechos Humanos. Revista internacional de derechos humanos, año $1, n^{\circ} 1$;

Skaar, E. (2011). Judicial independence and human rights in Latin America: violations, politics, and prosecution, Springer.

Surraco, L. (2013). Políticas públicas reparatorias dirigidas al universo de víctimas de graves violaciones a los derechos humanos y efectos de los prácticas sociales genocidas. Disponible en http://www.unsam.edu.ar/ciep [consultado el 05/01/2019]

Teitel, R. (2000). Transitional justice, Oxford, Oxford University Press

Teitel, R. (2003). Transitional justice genealogy, Harvard Human Rights Journal, Vol. 16

Villa Gómez, J. (2012). La acción y el enfoque psicosocial de la intervención en contextos sociales: ¿ podemos pasar de la moda a la precisión teórica, epistemológica y metodológica?, Agora USB, 12(2), 349-365.

van Boven, T. (2009). "Victims' rights to a remedy and reparation: the new United Nations principles and guidelines". En Reparations for victims of genocide, war crimes and crimes against humanity(pp. 17-40). Brill.

Valls, A. (2003). Racial Justice as Transitional Justice, Polity, 36/1, p. 53-71.

Wolfe, S. (2013). The politics of reparations and apologies, Springer Science \& Business Media. 